\title{
BMJ Open Estimates of price and income elasticity in Greece. Greek debt crisis transforming cigarettes into a luxury good: an econometric approach
}

Filippos Tarantilis, ${ }^{1}$ Kostas Athanasakis, ${ }^{1}$ Dimitris Zavras, ${ }^{1}$ Athanassios Vozikis, ${ }^{2}$ Ioannis Kyriopoulos ${ }^{1}$

To cite: Tarantilis F, Athanasakis K, Zavras D, et al. Estimates of price and income elasticity in Greece. Greek debt crisis transforming cigarettes into a luxury good: an econometric approach. BMJ Open 2015;5:e004748. doi:10.1136/bmjopen-2013004748

- Prepublication history for this paper is available online. To view these files please visit the journal online (http://dx.doi.org/10.1136/ bmjopen-2013-004748).

Received 23 December 2013 Revised 30 July 2014 Accepted 31 July 2014
CrossMark

\footnotetext{
${ }^{1}$ Department of Health Economics, National School of Public Health, Athens, Greece

${ }^{2}$ Department of Economics, University of Piraeus, Athens, Greece
}

Correspondence to Filippos Tarantilis; fil_t@hotmail.com

\section{ABSTRACT}

Objective: During the past decades, smoking prevalence in Greece was estimated to be near or over $40 \%$. Following a sharp fall in cigarette consumption, as shown in current data, our objective is to assess smokers' sensitivity to cigarette price and consumer income changes as well as to project health benefits of an additional tax increase.

Methods: Cigarette consumption was considered as the dependent variable, with Weighted Average Price as a proxy for cigarette price, gross domestic product as a proxy for consumers' income and dummy variables reflecting smoking restrictions and antismoking campaigns. Values were computed to natural logarithms and regression was performed. Then, four scenarios of tax increase were distinguished in order to calculate potential health benefits.

Results: Short-run price elasticity is estimated at -0.441 and short-run income elasticity is estimated at 1.040. Antismoking campaigns were found to have a statistically significant impact on consumption. Results indicate that, depending on the level of tax increase, annual per capita consumption could fall by at least 209.83 cigarettes; tax revenue could rise by more than $€ 0.74$ billion, while smokers could be reduced by up to 530568 and at least 465 smoking-related deaths could be averted.

Conclusions: Price elasticity estimates are similar to previous studies in Greece, while income elasticity estimates are far greater. With cigarettes regarded as a luxury good, a great opportunity is presented for decisionmakers to counter smoking. Increased taxation, along with focused antismoking campaigns, law reinforcement (to ensure compliance with smoking bans) and intensive control for smuggling could invoke a massive blow to the tobacco epidemic in Greece.

\section{INTRODUCTION}

\section{Country profile}

Globally, more than 5 million people die every year from tobacco use; tobacco use is the second leading cause of death, representing

\section{Strengths and limitations of this study}

- The article offers information to policymakers regarding price elasticity, a key measure to perform tobacco control policy.

- The article reports, for the first time, an income elasticity above 1 as evidence that cigarettes tend to be considered a luxury good in Greece.

- The analysis treats qualitative variables and projects health and financial benefits under extreme austerity.

- The analysis could not include dynamic (addiction) models, as no statistical significance was reported.

$8.7 \%$ of global annual mortality. ${ }^{1}$ As global tobacco consumption in 2009 was estimated at 5884 billion cigarettes, ${ }^{2}$ tobacco clearly reflects the global transition from traditional risks such as undernutrition, unsafe sex, unsafe water, poor sanitation and hygiene to modern risks including physical inactivity, behaviour risks and air quality. ${ }^{1}$ In Greece, WHO estimations attribute $17 \%$ of mortality for people aged 30 or older to smoking. ${ }^{3}$ Death rate attributed to tobacco and the proportion of deaths attributable to tobacco for ages 30 and over is documented in the following table (table 1).

A little less than half of the Greek population $(41 \%)$ smoke. ${ }^{4}$ The level of youth smoking is also high, $11.3 \%$ for young men and $9 \%$ for young women. ${ }^{2}$ Environmental Tobacco Smoke (ETS) also represents a serious problem in Greece, as documented by previous research. ${ }^{5}$

Concerning cigarette affordability, findings suggest that Greece is one of the few highincome European Union countries with relatively low cigarette prices. ${ }^{6}$ Low prices can be recognised as a factor for the tobacco epidemic in Greece. ${ }^{7}$ According to our calculations, for the period 1992-2012, cigarette 
Table 1 Estimated death rate (per 100000 ) and proportion attributable to tobacco for ages 30 years and over, 2004, in Greece ${ }^{3}$

\begin{tabular}{lcl}
\hline Cause of death & $\begin{array}{l}\text { Death rate } \\
\text { attributed } \\
\text { to tobacco }\end{array}$ & $\begin{array}{l}\text { Proportion of } \\
\text { deaths attributable } \\
\text { to tobacco (\%) }\end{array}$ \\
\hline $\begin{array}{l}\text { Lower respiratory } \\
\text { infections }\end{array}$ & 3 & 23 \\
$\begin{array}{l}\text { Malignant neoplasms } \\
\text { Cardiovascular diseases }\end{array}$ & 110 & 29 \\
Respiratory diseases & 90 & 12 \\
\hline
\end{tabular}

affordability, defined as the percentage of income needed to purchase 100 packs of cigarettes, was estimated to be from $0.56 \%$ to $1.98 \%$.

The first organised efforts to counter smoking in Greece were observed during 1979-1982. Currently, in Greece, tobacco advertising bans are complete, except for point-of-sale advertising.

Tax revenue from tobacco products is arguably very important for economic policy. In 1990, tax revenue accounted for $4.4 \%$ of gross domestic product (GDP). ${ }^{8}$ For the period 1998-2010, tobacco tax revenue stood at $2 \%$ annual average of GDP, but it seems to follow a downward trend.

Official estimates measure the total annual direct cost of smoking at $€ 2.14$ billion in an environment where debt crisis and austerity measures set serious constraints to the health system and where resources should, now more than ever, be allocated efficiently. ${ }^{9}$ Tobacco's unfavourable consequences on the poor could become a factor, where unemployment rates are estimated at $27.1 \%$ for the second quarter of 2013, and are continuing to grow from under 900000 to approximately 1350000 people in the past 24 months. ${ }^{10}$ Moreover, $31 \%$ of the total population is at risk of poverty or social exclusion. ${ }^{11}$

\section{Tobacco market and government interventions}

Three market failures differentiate an individual's choice to smoke compared to the decision to consume other goods: information failure on the health hazard of smoking, information failure on the addiction caused by smoking and external burden to non-smokers. ${ }^{12}$ Therefore, government intervention is justified in protecting smokers from the perilous habit and correct for externalities associated with smoking. From a basic economics standpoint, it can be claimed that the immense social burden of smoking overtakes the loss of consumer's utility and the loss of economic efficiency (deadweight loss).

Tobacco taxation is imposed through a variety of structures but, in nearly all cases, includes two main types of tax: ad valorem tax, which represents a percentage of price, and specific tax, which is a fixed tax per cigarette. In Greece, following the 2010 restructure of tobacco tax, total tax represents $86 \%$ of the retail price, significantly increased compared to the 2009 level and 2008 level when it represented $83 \%$ and $70 \%$ of the retail price, respectively. ${ }^{13}$ In 2012, specific excise tax was regulated at $€ 80$ per 1000 cigarettes and ad valorem tax at $20 \%$ of the retail price. The minimum sum is required to be no less than $€ 115$ per 1000 cigarettes. Meanwhile, a specific excise tax was set at $€ 153$ per $\mathrm{kg}$ of hand-rolled tobacco. Sales tax for cigarettes is fixed at $23 \%$ of the retail price.

Price increases should not be regarded as the only way to reduce consumption, as the impact of income, advertising and health education are also important. ${ }^{14}$ Manipulating these variables will result in reduced consumption and eventually reduced mortality and morbidity. Tobacco control programmes and policies are found to be either cost-saving or cost-effective, compared to other public health interventions such as cardiovascular risk counselling and cancer screening. ${ }^{15}$ Research on the impact of tobacco control showed that during 1981-2000, increases in tobacco control programme expenditures in the USA led to reduced cigarettes sales. Authors also suggest that expenditures have an even stronger lagged influence on sales. ${ }^{16}$ Smoking bans are adopted in order to limit exposure to smoke but they also cause a remarkable decrease in cigarette consumption, as opportunities to smoke are lessened. ${ }^{17}$ In Greece, the effort to restrict smoking in public places through legislation has failed due to low compliance with law. ${ }^{18}$ Youths exposed to secondhand smoke at home are estimated at $89.8 \%$ of total youth population. ${ }^{2}$ Public education campaigns, if "hard-hitting, sophisticated and sustained", can be extremely effective. ${ }^{13}$

\section{Price and income elasticity}

The term used to measure the impact of a change in price on consumption is price elasticity of demand, defined as the percentage change in consumption that results from $1 \%$ increase in price. ${ }^{19}$ Similarly, the impact of a change in income on consumption is measured by income elasticity, defined as the percentage change in consumption resulting from $1 \%$ increase in income. Estimating elasticity is crucial to policymakers in order to anticipate an intervention's impact on tobacco consumption as well as on tobacco tax revenue. If the proportionate fall in tobacco consumption exceeds the proportionate increase of tax, revenue will fall. Otherwise, revenue will rise. ${ }^{16}$

Results from a meta-analysis ${ }^{20}$ indicate that short run elasticity $(-0.40)$ is lower than long run elasticity $(-0.44)$, while in studies that included smuggling, demand was less sensitive $(-0.36)$. These findings confirm the general notion that a $10 \%$ increase in price would lead to a $4 \%$ reduction in consumption in high-income countries. ${ }^{18}$ Stavrinos $^{21}$ estimated the short run price elasticity at -0.079 and the long run at -0.147 , while income elasticity is estimated at 0.18 and 0.33 , respectively. Hondroyiannis and Papapetrou, based on data over the period 19671990 , calculated the short run price elasticity at -0.33 and the long run at -0.6 , while income elasticity estimations 
are 0.35 and 0.54 , respectively. The fact that demand is inelastic is explained by the authors through addiction and the absence of direct substitutes. Furthermore, it is claimed that health warnings are more effective than price increases in reducing consumption. ${ }^{9}$ Raptou et al conclude that, in an income elasticity of 0.28 , consisting of initiation elasticity (0.21) and consumption elasticity (0.07), income rather than consumption is a more important determinant for initiation. Furthermore, smoking bans are illustrated as a factor discouraging tobacco consumption. ${ }^{22}$ Nikolaou and Velentzas, based on data from 1960 to 1995, estimated the short run price elasticity at -0.24 and the long run at -0.48 , while income elasticity is estimated at 0.19 and 0.40 , respectively. Advertising had a positive but non-significant effect on demand and antismoking campaigns had a negative but non-significant effect on demand. ${ }^{23}$ On the other hand, health warnings on packs during 1987-1990 had a significant negative impact on demand, lowering consumption by $4.2 \%$. Dritsakis notes that consumption is a negative function of price and health education expenditure, and a positive function of income. ${ }^{24}$

As illustrated, there have been no studies of price elasticity now for at least a decade. In light of this, the purpose of the present study was to investigate cigarette demand in Greece.

\section{METHOD}

The tobacco products used in this analysis are cigarettes, which are widely accepted as the major tobacco product. In order to account for population growth, annual consumption per person over 15 was preferred to aggregate annual consumption. The threshold age was set at 15 , as the level of youth smoking in Greece is considered substantial. Data on annual cigarette consumption are available from 1994 onwards (1994-2012) from the Greek Ministry of Finance.

As excise tax data were not available and MPPC (Most Popular Price Category) shows inconsistency due to pricing policy, the measure chosen to reflect price was the Weighted Average Price. Each pack consists of 20 cigarettes. The proxy used to deflate nominal into real prices was calculated by comparing real and nominal values of GDP derived from World Bank. CPI (Consumer Price Index) was not selected as a proxy due to a change in calculations by Hellenic Statistical Authority in 1995, when a General Harmonized Consumer Price Index was introduced. The base year set was 2005. Disposable income data were based on GDP. Again, the threshold age was set at 15 . Therefore, deflation was not needed, as real values were available. Prior to 2008, national informative campaigns were not run in Greece at a national level. We considered The National Action Plan for Cancer (2008) as an antismoking campaign. ${ }^{9}$ A dummy variable was used to measure its influence on consumption. Expenditure on tobacco control was not available. Regulation for smoking bans and restrictions was only introduced in 2002 and amended in 2010. In order to measure its influence on consumption, an adjusted version of a previous reliable index was constructed, accounting not only for intensity of smoking restrictions but for compliance as well. ${ }^{25}$ Values attributed were between 0 (no restrictions) to 1 (total ban) escalating by 0.25 .

Data were analysed with the statistical software packages SPSSV.20 and STATAV.9. The functional form used in the analysis was Double-log and values were transformed to natural logarithms in order to increase reliability. The models of demand were specified as follows.

Conventional demand model

$$
\ln Q_{\mathrm{t}}=\mathrm{b}_{0}+\mathrm{b}_{1} \ln \mathrm{P}_{\mathrm{t}}+\mathrm{b}_{2} \ln \mathrm{Y}_{\mathrm{t}}+\mathrm{b}_{3} \mathrm{SR}_{\mathrm{t}}+\mathrm{b}_{4} \mathrm{AsC}_{\mathrm{t}}+\varepsilon_{\mathrm{t}}
$$

Myopic addiction model

$$
\begin{aligned}
\ln Q_{\mathrm{t}}= & \mathrm{b}_{0}+\mathrm{b}_{1} \ln \mathrm{P}_{\mathrm{t}}+\mathrm{b}_{2} \ln \mathrm{Y}_{\mathrm{t}}+\mathrm{b}_{3} \mathrm{SR}_{\mathrm{t}}+\mathrm{b}_{4} \mathrm{AsC}_{\mathrm{t}} \\
& +\mathrm{b}_{5} \ln \mathrm{Q}_{\mathrm{t}-1}+\varepsilon_{\mathrm{t}}
\end{aligned}
$$

Rational addiction model

$$
\begin{aligned}
\ln Q_{t}= & b_{0}+b_{1} \ln P_{t}+b_{2} \ln Y_{t}+b_{3} S R_{t}+b_{4} A s C_{t} \\
& +b_{5} \ln Q_{t-1}+b_{6} \ln Q_{t+1}+\varepsilon_{t}
\end{aligned}
$$

Where, $Q_{\mathrm{t}}$ : consumption of cigarettes per person over the age of 15 (000 cigarettes) in year $t$; $Q_{t-1}$ : consumption of cigarettes per person over the age of $15(000$ cigarettes) in year $t-1 ; Q_{t+1}$ : consumption of cigarettes per person over the age of 15(000 cigarettes) in year $t$ $+1 ; \mathrm{P}_{\mathrm{t}}$ : real retail price per pack of 20 cigarettes in year $\mathrm{t}$; $\mathrm{Y}_{\mathrm{t}}$ : real disposable income per person over the age of 15 $(€ 000)$ in year $t ; b_{0}$ : intercept in year $t ; \mathrm{SR}_{\mathrm{t}}$ : index of smoking restrictions or bans according to law in year $\mathrm{t}$; $\mathrm{AsC}_{\mathrm{t}}$ : dichotomous index reflecting the existence of an antismoking campaign each year $t ; \varepsilon_{\mathrm{t}}$ : the error term.

\section{RESULTS}

Through the conventional model of demand, the demand equation was estimated as follows (table 2).

A regression analysis was performed and calculations were made stepwise. The variable created to capture the effect of smoking restrictions was found non-significant ( $p$ value asymptotically equal to 0.303 at $5 \%$ confidence level); thus, it is excluded from the model. $\mathrm{p}$ Value at $5 \%$ confidence level is asymptotically equal to 0 for $\ln \mathrm{Y}_{\mathrm{t}}$, equal to 0.001 for $\ln _{\mathrm{t}}$ and equal to 0.021 for $\mathrm{AsC}_{\mathrm{t}}$. The F-statistic is high, showing a good level of fit, while the model explains a great part of the variation. The Durbin-Watson statistic is close to 2, suggesting that the model has no autocorrelation. The Variation Inflated Factor is low for all variables, implying that multicorrelation is a non-factor. As evidenced by normality tests, standardised residuals follow a normal distribution. Breusch-Pagan/Cook-Weisberg tests indicate that residuals are homoscedastic. The Augmented Dickey-Fuller test for standardised residuals confirms that no unit roots exist. Therefore, the standardised residuals 
Table 2 Conventional model of demand equation

$\ln Q_{t}=-1.757-0.441 \times \ln P_{t}+1.040 \times \ln Y_{t}-0.132 \times A s_{t}$

F-statistic: 27.765

$R^{2}: 0.847$

Durbin-Watson: 1.980

Skewness/Kurtosis tests for Normality: adj $\chi^{2}=5.10$, Prob $>\chi^{2}=0.0780$

Breusch-Pagan/Cook-Weisberg test for heteroskedasticity: $\chi^{2}=2.56$, Prob $>\chi^{2}=0.1093$

Dickey-Fuller test for unit root: $Z(t)=-2.364,1 \%$ critical value $=-2.660,5 \%$ critical value $=-1.950,10 \%$ critical value $=-1.600$

are stationary, so the variables of the model are cointegrated (without constant and trend) and the regression is not spurious. In light of the above, we accept a short-run price elasticity of demand at 0.441 and a short-run income elasticity of demand at 1.040 .

Through the myopic addiction model, the additional variable $\left(\ln Q_{t-1}\right)$ shows no statistical significance. Therefore, the model remains unchanged. Through the rational addiction model, only the variable representing the following year's consumption $\left(\ln Q_{t+1}\right)$ is found significant ( $\mathrm{p}$ value asymptotically equal to 0 ), with substantially lower levels of fit $\left(\mathrm{R}^{2}\right)$. Thus, we conclude that addiction models fail to offer additional information on how consumption is influenced. Based on 2010 data, nominal tax revenue per pack is calculated at $€ 2.78$, a value verifying and corresponding to the fixed amount of tax ( $86 \%$ of the nominal retail price). We assume that the state maintains the existing ability to collect revenue. Government proclamations suggest that tobacco will be further taxed. Therefore, we introduce four distinct scenarios, all with retail price increases, as anticipated and each suggesting an additional price increase by $€ 0.5$. Calculations are made only for the following year and accordingly only short run elasticity is taken into account. The scenarios capture the impact of the continuing fall in income at a rate of $4.8 \%$. Based on the methodology and data put forward by Ross et $a l^{26}$ concerning tobacco-related mortality in Greece (lower respiratory infections, malignant neoplasms, cardiovascular diseases and respiratory diseases), we estimate a reduction in smokers and lower mortality. ${ }^{3}$

In all four scenarios, consumption is decreased substantially while tax revenue is still increased thanks to the inelastic demand. Moreover, smokers are significantly reduced and smoking-related deaths are accordingly limited (table 3).

\section{DISCUSSION}

Price elasticity estimates are greater than previous research in Greece, ${ }^{823}$ but consistent with findings by Gallet and List. $^{20}$ Estimates for income elasticity are far greater than estimates provided by the literature in Greece. ${ }^{8}$ 21-23 Regarding antismoking campaigns, results are in agreement with previous testimony. ${ }^{23}{ }^{24}$ Smoking restrictions show no statistical significance, confirming the claims by Joosens and $\operatorname{Raw}^{18}$ that compliance is low. Finally, results are in general agreement with Alpert et $a l^{27}$ though a different methodology is followed.

Paired with the still high cigarette affordability, as documented in the current study and reported by previous research, ${ }^{6}$ the nature of demand in Greece presents a vast opportunity for policymakers to counter the tobacco epidemic, and ensure revenue and cash flow at the same time. Even supposing that other determinants of demand, such as income, which is anticipated to fall,

Table 3 Impact of price increase and income constraints on consumption, tax revenue, number of smokers and smoking-related deaths

\begin{tabular}{|c|c|c|c|c|}
\hline Model scenarios & Scenario 1 & Scenario 2 & Scenario 3 & Scenario 4 \\
\hline Price per pack & $€ 4.47$ & $€ 4.97$ & $€ 5.47$ & $€ 5.97$ \\
\hline Percent increase of price & $12.59 \%$ & $25.19 \%$ & $37.78 \%$ & $50.38 \%$ \\
\hline Fall in consumption due to price increase & $-5.55 \%$ & $-11.11 \%$ & $-16.66 \%$ & $-22.22 \%$ \\
\hline Fall in consumption due to income decrease & $-4.99 \%$ & $-4.99 \%$ & $-4.99 \%$ & $-4.99 \%$ \\
\hline Per capita consumption level & 1779.84 & 1669.33 & 1558.82 & 1448.31 \\
\hline Per capita consumption deterred & 209.83 & 320.34 & 430.85 & 541.36 \\
\hline Tax revenue per pack & $€ 3.84$ & $€ 4.27$ & $€ 4.70$ & $€ 5.13$ \\
\hline Tax revenue per cigarette & $€ 0.192$ & $€ 0.214$ & $€ 0.235$ & $€ 0.257$ \\
\hline Total tax revenue ( $€$ billion) & $€ 3336$ & $€ 3478$ & $€ 3575$ & $€ 3625$ \\
\hline Incremental tax revenue ( $€$ billion) & $€ 0455$ & $€ 0597$ & $€ 0694$ & $€ 0744$ \\
\hline Reduction in number of smokers & 205650 & 313956 & 422262 & 530568 \\
\hline \multicolumn{5}{|l|}{ Smoking-related deaths averted } \\
\hline High $(0,50)$ & 930 & 1420 & 1911 & 2401 \\
\hline Low $(0,25)$ & 465 & 710 & 955 & 1200 \\
\hline
\end{tabular}

Differences in calculations may occur due to rounding.

Impact of price increase shared between prevalence and consumption.

High estimate indicates that $50 \%$ of smokers' deaths are attributable to tobacco use, whereas low estimate indicates that $25 \%$ of smokers' deaths are attributable to tobacco use. 
do not change, tobacco taxation proves to be a powerful tool. Annual consumption per person over 15 would be no higher than 1780 cigarettes, even in the worst case (scenario 1) and may fall to less than 1448 cigarettes. On the other hand, tax revenue would recover from the downward trend, accounting again for more than $1.80 \%$ of GDP, even in scenario 1. In absolute values, excess tobacco tax revenue could rejuvenate the dismantled public coffers. Results suggest that even with a modest $10 \%$ of tax revenue allocated to offsetting the tobacco epidemic, there would be more than enough disposable funds towards planning, implementing, evaluating and improving antismoking efforts. Greeks seem to be in agreement with heavy taxation on cigarettes, but only if respective revenue is attributed to tobacco control. ${ }^{28}$ In terms of public health benefits, smokers could be reduced by nearly 530568 people, while up to 2401 smoking-related deaths could be averted on an annual basis. Nonetheless, findings should be treated with caution and price should not be excessively increased from day one, as smokers' reaction is not easy to predict with CIs widened. A stepwise increase of tax would eliminate many of the risks associated with a sharp and sudden increase in cigarette prices. Besides, Greece already performs better in tax collection than countries such as Germany, France and Slovenia, among others, ${ }^{26}$ as the excise per smoker ratio indicates, with $€ 738.71$ collected for every smoker.

Income sensitivity is larger than in any previous study either in Greece or internationally. Thus, it is not exaggerating to argue that Greek smokers are shocked by the constraint on their income. Besides, it is the first time in at least 40 years that income in Greece is falling at this rate. The austerity measures should be viewed as a shift event in cigarette consumption, among others.

Reducing the toll of tobacco in Greece is not an easy task. Decisions should include fostering an antismoking culture through well-planned national antismoking campaigns, raising cigarette prices at an initial level no less than $€ 4$ a pack and ensuring compliance with antismoking laws, especially now, as the City Police force (the main mechanism of control on the matter) was recently abolished as an institution. Controlling illicit trade is crucial to maximise the effect of interventions.

As regards the limitations of this study, it must be noted that addictions models were unable to provide statistically significant information, possibly due to the inclusion of 2012 data in the time series. Possible future analysis of an even wider time series could provide even more reliable results, as multicollinearity could be fully avoided. Furthermore, the study could be strengthened by employing statistical tests on more observations regarding the endogeneity of cigarette prices. Moreover, the current study is based on the most popular price category in order to estimate the impact of price changes on cigarette demand. It is possible that a weighted average for all the brands sold in Greece could eliminate unilateralism on price data. Still, the anticipated but not fully documented switch of Greek smokers from manufactured cigarettes to hand-rolled tobacco should be taken into account in any future research. However, if the increase of contraband cigarettes in the Greek market could be quantified, results would be more punctual. In addition, tobacco shows a synergistic effect with other substances, such as alcohol. Thus, it would be meaningful to investigate the combined effect of tobacco and alcohol from an economic aspect. Finally, researchers argue that the increased availability of nicotine substitutes will reduce demand for tobacco products and increase the price sensitivity as well. ${ }^{19}$ Under that scope, if research included nicotine substitutes, accuracy would be improved.

Acknowledgements The authors would like to express their gratitude to Professor Frank Chaloupka for his valuable and constructive suggestions towards planning and development of this research work. His willingness to provide us his valuable time has been very much appreciated.

Contributors FT, DZ and AV performed the calculations and analyses reported in the text. FT and KA reviewed the literature for relevant data and documentation. FT and KA drafted the manuscript, which was edited and critically revised by KA, AV and IK.

Funding This research received no specific grant from any funding agency in the public, commercial or not-for-profit sectors.

Competing interests None.

Provenance and peer review Not commissioned; externally peer reviewed.

Data sharing statement $E$ Inputs of the analysis include aggregate cigarette consumption, population, price and Gross Domestic Product. Moreover, dummy variables of the analysis are based on the Greek National Plan against Cancer (http://www.epaac.eu/national-cancer-plans) and the Greek legislation (Law 3730/2008, effective from 23/12/2008 onwards and Law 3868/2010, effective from 3 August 2010 onwards, both available at Government Gazettes (http://www.et.gr/)). Unfortunately, aggregate cigarette consumption and weighted average price for the period 1994-2012 are official but remain unpublished by the Greek Ministry of Finance. Therefore, they are available on request from the lead author (FT, fil_t@hotmail.com). Owing to the Ministry's often changing policy in terms of providing information to the public, we rejected the option to share data in Dryad data repository. Finally, Greek population and Gross Domestic Product for the aforementioned period was derived from the World Bank database (http://data.worldbank.org/).

Open Access This is an Open Access article distributed in accordance with the Creative Commons Attribution Non Commercial (CC BY-NC 3.0) license, which permits others to distribute, remix, adapt, build upon this work noncommercially, and license their derivative works on different terms, provided the original work is properly cited and the use is non-commercial. See: http:// creativecommons.org/licenses/by-nc/3.0/

\section{REFERENCES}

1. WHO. Global health risks: mortality and burden of disease attributable to selected major risks. Geneva: World Health Organization, 2009. http://www.who.int/healthinfo/global_burden disease/GlobalHealthRisks_report_full.pdf (accessed 14 Nov 2011).

2. Eriksen M, Mackay J, Ross H. The tobacco atlas. 4th edn. Atlanta, GA: American Cancer Society, New York: World Lung Foundation, 2012.

3. WHO. WHO Global report: mortality attributable to tobacco. Geneva: World Health Organization, 2012. http://whqlibdoc.who.int/ publications/2012/9789241564434_eng.pdf (accessed 5 Oct 2012).

4. Filippidis FT, Vardavas $\mathrm{Cl}$, Loukopoulou A, et al. Prevalence and determinants of tobacco use among adults in Greece: 4 year trends. Eur J Public Health 2013;23:772-6.

5. Vardavas $\mathrm{Cl}$, Kondilis $\mathrm{B}$, Travers $\mathrm{MJ}$, et al. Environmental tobacco smoke in hospitality venues in Greece. BMC Public Health 2007;7:302.

6. Blecher EH, Van Walbeek CP. Cigarette affordability trends: an update and some methodological comments. Tob Control 2009;18:167-75. 
7. Vardavas $\mathrm{Cl}$, Kafatos AG. Smoking policy and prevalence in Greece: an overview. Eur J Public Health 2007:17:211-13.

8. Hondroyiannis G, Papapetrou E. Cigarette consumption in Greece: empirical evidence from cointegration analysis. Applied Econ Lett 1997;4:571-4.

9. Ministry of Health and Social Solidarity. The Greek National Plan of Action against Cancer 2008-2012, Athens, 2008. http://ygeiamap. gov.gr/wp-content/uploads/2013/05/karkinos_teliko.pdf (accessed 5 Oct 2011).

10. Hellenic Statistical Authority, Workforce research, Press release 19 September. 2013. http://www.statistics.gr/portal/page/portal/ESYE/ BUCKET/A0101/PressReleases/A0101_SJO01_DT_QQ_02_2013 01_F_GR.pdf (accessed 7 Nov 2013).

11. Eurostat news release 26 February 2013, Eurostat press office. http://europa.eu/rapid/press-release_STAT-13-28_en.htm (accessed 27 Feb 2013)

12. Wilkins N, Yurekli A, Hu TW. Economic analysis of tobacco demand Economics of tobacco toolkit. Washington: World Bank, 2004. http:// siteresources.worldbank.org/INTPH/Resources/3Demand.pdf (accessed 24 Nov 2011).

13. WHO. Report on the Global Tobacco Epidemic, 2008: The MPOWER package. Geneva: World Health Organization, 2008. http://www.who.int/tobacco/mpower/mpower_report_full_2008.pdf (accessed 14 Nov 2011).

14. Godfrey C, Maynard A. Economic aspects of tobacco use and taxation policy. BMJ 1998;297:339-43.

15. Kahende JW, Loomis BR, Adhikari B, et al. A review of economic evaluations of tobacco control programs. Int J Environ Res Public Health 2009;6:51-68.

16. Farrelly M, Bray J. Responses to cigarette tax increases by race/ ethnicity, income and age groups-United States, 1976-1993. J Am Med Assoc 1999;280:1979-80.
17. Chaloupka F, Warner E. The economics of smoking. Handb Health Econ 2000;1:1539-627.

18. Joossens L, Raw M. The tobacco control scale 2010 in Europe Brussels: Association of European Cancer Leagues, 2011.

19. Chaloupka F, Pacula R. The impact of price on youth tobacco use. Changing adolescent smoking prevalence: where it is and why, smoking and tobacco control monograph. 1999:14.

20. Gallet C, List J. Cigarette demand: a meta-analysis of elasticities. Health Econ 2003;12:821-35.

21. Stavrinos VG. The effects of an anti-smoking campaign on cigarette consumption: empirical evidence from Greece. Appl Econ 1987;19:323-9.

22. Raptou E, Mattas K, Tsakiridou E, et al. Factors affecting cigarette demand. Int Adv Econ Res 2005;11:275-90.

23. Nikolaou A, Velentzas K. Estimating the demand for cigarettes in Greece: an error correction model. Agric Econ Rev 2001;2:20-7.

24. Dritsakis E. Forecasting of cigarettes consumption in Greece: an empirical investigation with cointegration analysis. Agric Econ Rev 2003;4:47-56.

25. Wasserman J, Manning WG, Newhouse JP, et al. The effects of excise taxes and regulations on cigarette smoking. $J$ Health Econ 1991;10:43-64.

26. Ross HZ, Shariff S, Gilmore A. Economics of tobacco taxation in Russia. Paris: International Union Against Tuberculosis and Lung Disease, 2008.

27. Alpert HR, Vardavas $\mathrm{Cl}$, Chaloupka FJ, et al. The recent and projected public health and economic benefits of cigarette taxation in Greece. Tob Control 2014;23:452-4.

28. Vardavas $\mathrm{Cl}$, Filippidis FT, Agaku I, et al. Tobacco taxation: the importance of earmarking the revenue to health care and tobacco control. Tob Induc Dis 2012;10:21. 